\title{
Possible Sensory Endings in the Submucous Plexus of Mouse Small Intestine
}

\author{
By \\ MaSARU YAMAMOTO \\ Department of Anatomy, Teikyo University School of Medicine, \\ Itabashi, Tokyo 173, Japan \\ - Received for Publication, January 30, 1980--
}

Key Words: Sensory ending, Small intestine, Submucous plexus, Neurotubule.

\begin{abstract}
Summary. Mitochondria-rich varicosities of unmyelinated nerve fibers are found in the submucosa of the mouse small intestine, and are consieered sensory endings. They appear in the submucous plexus as well as in the myentric plexus. The endings also contain abundant elongated dumbbell-shaped vesicles (about $250 \AA \times 1500 \AA$ ) but are devoid of small granular and agranular vesicles as seen in autonomic endings. The possibility that the dumbbellshaped vesicles might be derived from neurotubules is discussed.
\end{abstract}

\section{Introduction}

Nerve terminals or varicosities containing abundant, small mitochondria (about $0.2 \mu \mathrm{m}$ in diameter) are present in various types of sensory receptors (Cauna, 1969; Smith, 1970; Suzuki and Kurosumi, 1972; T. Yamamoto, 1966 ; etc.). They are thus considered sensory endings. Such mitochondria-rich (MR) endings have also occasionally been found in smooth muscle (Burnstock, 1972; etc.), in the tracheobronchial epithelium (Hung, 1976), and in the intestinal myenteric plexus (Gabella, 1972 ; Yamamoto, 1977). Gabella suggested that the similar endings found in the myenteric plexus of guinea-pig ileum might be sensory. Similar accumulations of mitochondria, are scarcely noticeable in autonomic terminals. These MR-endings may possibly be referred to as sensory in nature.
Sensory fibers are also known to occur in the submucosa of the small intestine (Gunn, 1968; Bülbring et al., 1958; etc.) but their ultrastructure remains unknown. Gosling and Dixon (1974) observed in the submucous tissue of the mammalian urinary tract, many endings or varicosities which contained small agranular vesicles and exhibited cholinesterase activity. They considered such endings sensory. MR-endings, however, have not so far been reported in the submucosa of mammalian intestine.

\section{Material and Methode}

Six domestic white mice of both sexes were used. The wall of the small intestine was cut into small pieces and fixed in $2.5 \%$ glutaraldehyde in cold buffer solution (0.1 M phosphate buffer, pH 7.4, 5\% sucrose) for either $30 \mathrm{~min}$ or 2 hours. 
Fixed samples were washed overnight in the above cold buffer solution. After post-fixation in $1-2 \% \mathrm{OsO}_{4}$ in cold buffer solution for 1 hour, the samples were dehydrated in ascending concentrations of ethanol and infiltrated with Spurr's resin. Ultrathin sections were cut on a Porter-Blum microtome using glass knives and stained with uranyl acetate and Sato's lead solution (Sato, 1969). They were observed under a JEM $100 \mathrm{C}$ electron microscope.

\section{Results}

One or more MR-varicosities which possibly represented the sensory endings were observed in almost all the small intestinal submucous (Figs. 1,2) or myenteric plexuses of the mouse in the sections employed for examination. These were sometimes in close contact with the perikaryon of the myenteric ganglion cell (Yamamoto, 1977) or in synaptic contact with dendritic processes of the submucous plexus (Fig. 2). Although the MR-ending was enveloped by the Schwann cytoplasm, its surface plasma membrane area facing the synaptic cleft of about $250 \AA$ in width became naked and formed the presynaptic membrane which was closely apposed in parallel to the postsynaptic membrane of the dendrite. The pre- and postsynaptic membranes were characterized by thickening and density increase (Fig. 2). Elongated dumbbell-shaped vesicles, another inclusion of the MR-ending, were accumulated towards the synaptic pole of the ending, and so they might be referred to as synaptic vesicles (Fig. 2).

The presumed sensory varicosities contained abundant small round or oval mitochondria which were characterized by a paucity of cristae. The more or less elongated dumbbell-shaped vesicles which might represent the synaptic vesicles of the MR-endings were similar in width and structure to neurotubules and contained an occasional dense bar (or core) in the center (Fig. 3). They measured up to about $1500 \AA$ in length and $250 \AA$ in width, and usually bore a slight swelling at both ends to form the dumbbell-shape (Figs. 2, 3). This represented one of the ultrastructural differences from the ellipsoidal (or flat) vesicles known to exist in inhibitory synapic terminals (Uchizono, 1965).

\section{Discussion}

As pointed out in the introduction to this paper, the sensory endings or varicosities (swellings) of nerve fibers found in various sensory receptors are characterized by abundant small mitochondria. The present paper marks the first report of MR-varicosities in the submucosa of mouse small intestine which are characterized not only by an abundance of small mitochondria but also by many densely packed elongated dumbbellshaped vesicles. Since it has been shown electrophysiologically that functional sensory endings exist in the intestinal tract (Hirst et al., 1974), the MR-varicosities described here may reasonably be regarded as one type of intramural sensory endings. These varicosities or endings, however, are different in ultrastructure from the sensory endings in the submucosa of the mammalian urinary tract which contain small agranular vesicles and exhibit cholinesterase activity, as shown by Gosling and Dixon (1974). Their socalled sensory endings containing round agranular vesicles and a few mitochondria appear rather to agree in ultrastructure with typical cholinergic ones.

The presumed sensory endings reported in this paper are characterized, as mentioned above, by abundant peculiar dumbbell-shaped vesicles, which are morphologically distinct from the flat vesicles 
revealed by Uchizono (1965) in inhibitory synaptic terminals. Recently, Sugawara and Kanaseki (1976) demonstrated that conversion of spherical agranular synaptic vesicles into the flat type may be induced under a high concentration of $\mathrm{Ca}^{++}(30$ $\mathrm{mM})$ and high fixation temperature $\left(20^{\circ} \mathrm{C}\right)$. Our samples, however, were fixed at 0 $4^{\circ} \mathrm{C}$ in a solution containing no excessive $\mathrm{Ca}^{++}$. Moreover, the flat vesicles revealed by them were wider and shorter than the dumbbell-shaped ones (Sugawara, personal communication). The peculiar elongated dumbbell-shaped vesicles are expected to play an important role in the reception or conduction of sensory stimuli (Suzuki and Kurosumi, 1972). As to the origin of the synaptic vesicles, discussions have been presented by various authors, some of whom (Gray, 1976; etc.) stated that the vesicles might originate from the smooth endoplasmic reticulum of the neuron. Several other authors (Umahara, 1968 ; etc.), however, have proposed that the vesicles might be derived from neurotubules. This hypothesis could be applicable to the mechanism of formation of the peculiar elongated, possibly tubular, dumbbell-shaped vesicles which bear almost the same caliber as neurotubules, although the electron density of the content or matrix of the dumbbell-shaped structures is somewhat higher than that of neurotubules. This finding suggests that they might contain some transmitter substance which could be released in the synaptic cleft in response to stimuli.

\section{Acknowledgement}

The author wishes to express his sincere thanks to Prof. T. Ito for his helpful advice in preparing the manuscript, and also to Prof. K. Uchida for her constant interest and encouragement.

\section{Ref erences}

1) Bülbring, E., Lin, R.C.Y. and Schofield, G.: An investigation of the peristaltic reflex in relation to anatomical observation. Quart. J. Exp. Physiol. Cognate Med. Sci. 43 : 26-37, 1958.

2) Burnstock, G.: Purinergic nerves. Pharmacol. Rev. 24 : 508-581, 1972.

3) Cauna, M.: The fine morphology of the sensory receptor organs in the auricle of the rat. J. Comp. Neur. 136:81 98, 1969.

4) Gabella, G.: Fine structure of the myenteric plexus in the guinea pig ileum. J. Anat. 111: 69-97, 1972.

5) Gosling, J.A. and Dixon, J.S.: Sensory nerves in the mammalian urinary tract. J. Anat. 117 : 133-144, 1974.

6) Gray, E.G.: Presynaptic microtubules, agranular reticulum and synaptic vesicles. In: Synapses (G.A. Cottrell and P.N.R. Usherwood, eds.), pp. 6-18. GlasgowLondon: Blackie, 1976.

7) Gunn, M.: Histological and histochemical observations on the myenteric and submucous plexuses of mammals. J. Anat. 102: 223-239, 1968.

8) Hirst, G. D.S., Holman, M. E. and Spence, I: Two types of neurones in the myenteric plexus of duodenum in the guinea pig. J. Physiol. 236: 303.326, 1974.

9) Hung, K.-S.: Fine structure of tracheobronchial epithelial nerves of the cat. Anat. Rec. 185: 85-92, 1976.

10) Sato, T.: A modified method for lead staining of thin sections. J. Electron Microsc. 17: 158-159, 1968.

11) Smith, K.R.: The ultrastrucutre of the human Haarsheibe and Merkel cell. J. Invest. Derm. 54 : 150-159, 1970.

12) Sugawara, Y. and Kanaseki, T.: A combined physiological and electron microscope study of the electroreceptor of marine catfish, Plotosus anguillaris (Lacēpēde), with special reference to the mechanism of afferent transmissions. J. Electron Microsc. 25: 214-215, 1976.

13) Suzuki, H. and Kurosumi, K.: Fine structure of the cutaneous nerve endings 
in the mole snout. Arch. Histol. Jap. $34: 35-50,1972$.

14) Uchizono, K.: Characteristics of excitatory and inhibitory synapses in the central nervous system of the cat. Nature 207: 642-643, 1965.

15) Umahara, Y.: Light and electron microscopic studies on the brown adipose tissue in the bat. Arch. Histol. Jap. 29: 459-509, 1968.
16) Yamamoto, M.: Electron microscopic studies on the innervation of the smooth muscle and the interstitial cell of Cajal in the small intestine of mouse and bat. Arch. Histol. Jap. 41: 171-201, 1977.

17) Yamamoto, T.: The fine structure of the palisade-type sensory endings in relation to hair follicles. J. Electron Microsc. 15 : 158-166, 1966. 


\section{PLATE}




\section{Explanation of Figures}

\section{Plate I}

Fig. 1. A portion of the submucous plexus in mouse small intestine. Two mitochondria-rich endings (S) and two autonomic ones (C) characterized by small agranular vesicles are seen. They are partially surrounded by thin Schwann cytoplasm (SC). Ganglion cell (G). $\times 13,000$.

Fig. 2. Higher magnification of part of Fig. 1 containing two mitochondria-rich endings (S). Dumbbell-shaped vesicles (arrows) are densely accumulated towards the synaptic pole of the ending on the right side, the naked bottom surface of which forms a synapse with the apposed plasma membrane of a dendrite (D). Thickening and density increase of both the pre- and postsynaptic membranes are seen. Axon (A), large dense cored vesicle (LC), mitochondria (M), Schwann cytoplasm (SC). $\times 30,000$.

Fig. 3. A highly magnified MR-ending closely packed with abundant dumdbbell-shaped synaptic vesicles. The ending is enveloped by thin Schwann cytoplasm (SC). The matrix of the vesicles is moderately electron dense and contains an occasional electron dense bar (B). Large dense cored vesicle $(\mathrm{LC})$, mitochondria $(\mathrm{M}) . \times 60.000$. 

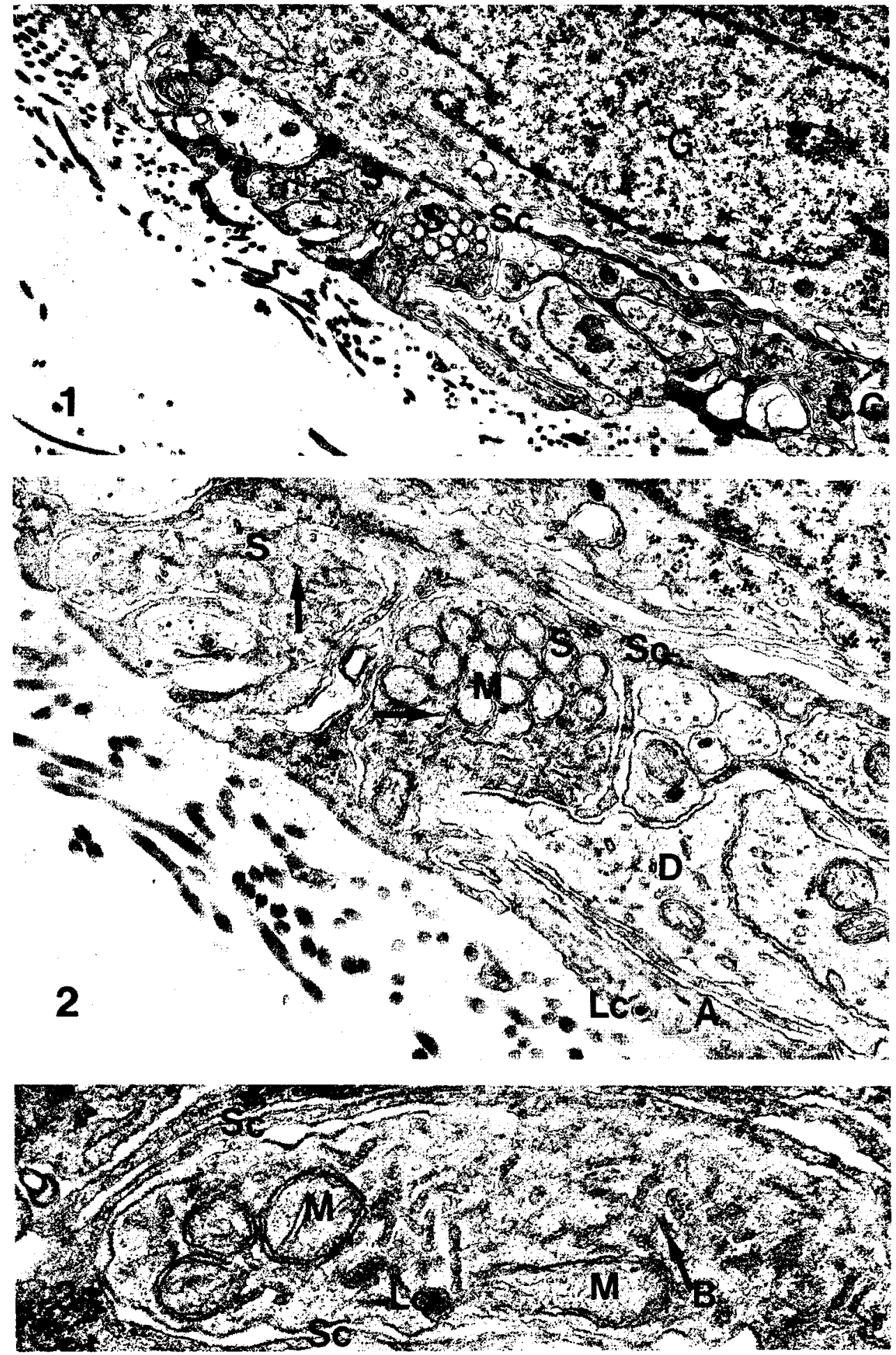